\title{
DIVERSIDAD CULTURAL, CONTEXTO FRONTERIZO Y FORMACIÓN DE DOCENTES EN EDUCACIÓN BÁSICA DE MÉXICO
}

\author{
María Celina Aguirre Ibarra \\ Doctora en Psicoterapias existenciales, \\ Instituto de Terapia Guestal Región Occidente \\ Universidad Autónoma de Baja California, \\ mariacelina@uabc.edu.mx \\ Enrique Mata González \\ Doctor en Ciencias de la Educación \\ Universidad Iberoamericana Tijuana \\ Universidad Pedagógica Nacional, México \\ emata57@yahoo.com
}

\section{Cómo citar este artículo}

Aguirre, M. y Mata, E. (2013) Diversidad cultural, contexto fronterizo y formación de docentes en Educación Básica de México. Espiral, Revista de docencia e Investigación. 3 (1) 15 - 32

\begin{abstract}
Resumen
La diversidad cultural y la educación básica en México implican el desarrollo de una pedagogía fronteriza que impulse la reflexión del proceso de formación de docentes, que dé cuenta de la realidad educativa como fenómeno dinámico de alta complejidad y multidiversidad. Es necesario construir el conocimiento desde la práctica educativa que vincule teoría-práctica, y asumir el reto a través de una metodología crítica como es la investigaciónacción. La formación de docentes resulta valiosa cuando se mejora la práctica, y se reconoce la experiencia y la construcción de sí mismos. Su valoración y acercamiento a través de la investigación, posibilita pasar de manera colaborativa de la reflexión a la acción. Es fundamental la reflexión y conocimiento de la práctica del/la docente cotidianamente repetida, durante el proceso mismo de la formación docente, para que su experiencia sea generadora e incluyente en la diversidad. Desde esta perspectiva, la diversidad cultural expresada en el aula necesita ser atendida como elemento central y punto de partida de la práctica educativa. En este sentido el propósito es ofrecer a docentes en educación básica reflexiones sobre la formación docente orientada a tener presente la importancia de la diversidad cultural en el aula escolar.
\end{abstract}

Palabras clave: Diversidad cultural, contexto fronterizo, formación de docentes, globalización, investigaciónacción.

\footnotetext{
Abstract

The point of cultural diversity and basic education in Mexico involves the development of a border pedagogy that encourages reflection towards teacher training pro-
}

cess where the teachers will have to give account of the educational and high dynamic phenomenon complexity and multi-diversity. It is necessary to build the knowledge from educational practice that links theory and practice, and delve into the challenge through a critical methodology as action-research. That Teacher training is valuable when improving practice, and recognizes the experience and construction of themselves as persons is that. Your assessment and approach through research, enables collaboratively move from reflection to action. Reflection is essential and knowledge of practice the teacher daily repeated during the process of teacher training to make your experience generating and inclusive diversity. From this perspective, cultural diversity in the classroom has expressed that needs to be addressed as a central element and starting point as educational practice. In this sense, the purpose is to provide basic education teachers reflections on teacher training oriented to keep in mind the importance of cultural diversity in the classroom.

Keywords: Identity cultural, border context, teacher training, globalization, action-research.

\section{INTRODUCCIÓN}

La diversidad del contexto fronterizo que se presenta en Baja California, México, se caracteriza por una gran confluencia intercultural que beneficia la expresión de diversas formas de ser y hacer en la convivencia, reconocida como un valor esencial. Atender a la población haciendo énfasis en estas diferencias es confiar en encontrar algunas pautas de conexión dentro 
de la diversidad, estableciendo formas de vida cotidiana como reto colectivo.

La propuesta educativa de regionalización (como un apéndice a la tendencia general homogeneizadora denominada globalización) enmarcada dentro de una pedagogía fronteriza, apunta a la constitución del ser humano y a su posicionamiento dentro de la matriz cultural, es decir, una visión antropológica y social de la persona sin dejar de lado su peculiaridad.

Establecer un diálogo identificador de los elementos que se ponen en juego en la frontera, es propiciar nuevos significados hacia el fomento de la identidad fronteriza y expansión de límites que pueden ir desde la inclusión de la variación interna hasta el punto de contacto, sumersión y traspaso de dichos límites del país vecino, como lo es Estados Unidos de América, con una verdadera construcción del espacio fronterizo para el desarrollo humano, que apunta a mejorar la vida cotidiana de las personas en relación y más cuando ésta se hace presente en las aulas a través de una mirada pedagógica y con la mediación que corresponde.

Las escuelas, los/las docentes y los mismos procesos de formación de docente no ayudan mucho a la integración de esta realidad de ser fronterizo vivido, experimentado y sentido. En las escuelas no les interesa la necesidad reflexionada del sentido cotidiano y de la convivencia como base de esa identidad. No se reflexiona por ejemplo, sobre la reproducción de fronteras al interior de la escuela y de la persona misma, porque se vive un presente inmediato que no la favorece y al que se debe atender de inmediato, porque el momento es ahora y no esperar cuando la situación ha desbordado toda posibilidad de solución pertinente.

Las investigaciones en la actualidad indican que este trabajo no se está haciendo $y$, por lo contrario, se asoman al interior, donde prevalecen manifestaciones de exclusión de amplios sectores de población y de diversos tipos. En los planes de estudio de las escuelas de educación básica, media y superior, observamos que predomina un proyecto educativo donde se ignora el contexto. A esto se le agrega la falta de reflexión y discusión crítica sobre la problemática social, económica y política que afecta el acontecer de la vida cotidiana y a la colectividad. Por otra parte, la práctica educativa que se despliega en el aula no hace efectiva una educación centrada en la persona, ni apunta a la realización del ser potencial interesándose en su desarrollo integral.

Por lo mismo, es frecuente que la educación que integra valores, no los relaciona con los valores que adquieren sustancia como, por ejemplo, en el diálogo de situaciones vividas. La necesidad de identidad fronteriza incluye valores ambientales, socioculturales y fronterizos. Es decir, la necesidad de reconocimiento político cultural, económico, ético y educativo de lo fronterizo que afecta intereses, compromete y determina posturas en nosotros como mexicanos, que si bien ubicados lejos del centro del país, nos encontramos en estas latitudes muy atentos a lo que sucede en el interior y exterior, siendo esto muy significatvo en la conformidad de la identidad del mexicano fronterizo.

La investigación en diferentes escuelas primarias y secundarias locales, en general, indica que la diversidad priva al interior de las instituciones públicas y que, a su vez, propicia diferenciaciones muy precisas que en su mayor parte son apreciaciones despectivas y de discriminación ejercidas con violencia, cuya función es observada como la replicación de los valores del mercado, empecinados en marcar y mantener diferencias con las cuales competir por un mayor estatus dentro del contexto escolar (Ochoa, 2004).

La importancia del estudio antes mencionado radica en orientarnos hacia una educación interesada por la integración de la diversidad, 


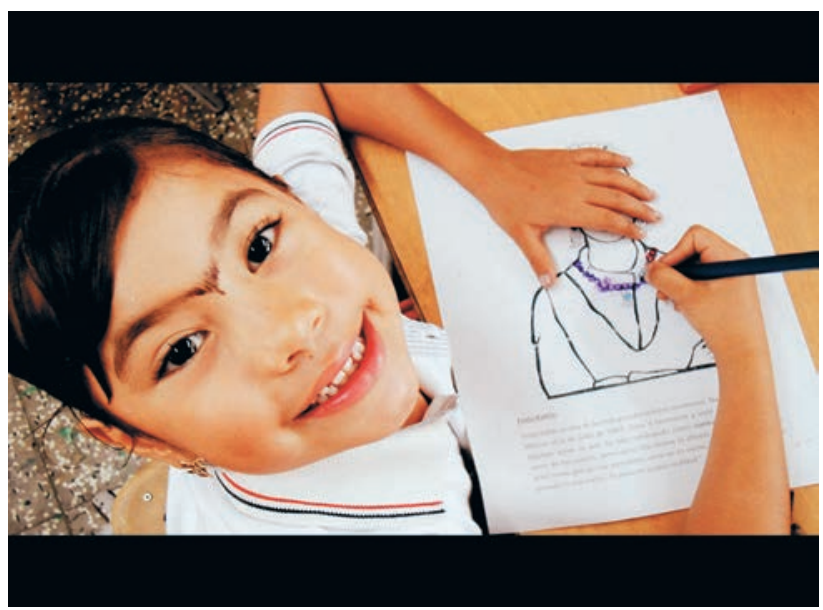

a partir del reconocimiento de las diferencias, como aquellas distintas formas de exclusión desplegadas en el cotidiano vivir que conducen a la separación y a la violencia y que son formas relacionales consideradas dentro los estándares normales, porque ya no hay la sorpresa ante tanta injusticia y menos cuando no me llama en absoluto el sufrimiento y el desamparo de mis semejantes, compañeros, amigos, vecinos, estudiantes y un largo etcétera.

En otras investigaciones se ha reportado un análisis revelador acerca de las arbitrariedades culturales, donde los/las docentes hacen uso de su poder y fomentan relaciones de sumisión y homogeneización en y con los estudiantes (Martínez, 2005). Porque el ejercicio del poder, de la autoridad y mando, se ve como normal en personajes como el/la docente, porque se ha llegado a tal grado de violencia, que de no hacerlo así, socialmente es cuestionada su labor y desempeño, se valora como debilidad y por tanto se percibe como no apto para el ejercicio de la docencia.

La tendencia a la deshumanización y exclusión social continúa y el mundo de los empobrecidos aumenta. Es necesario aterrizar el discurso a través del pensamiento crítico situado y orientado a la práctica, para abordar la realidad con conciencia crítica y social. Es más que evidente que así como vamos, no hay salida a este atolladero, cada vez nos acercamos más y más al abismo de la ignorancia, la barbarie, y a la ley del más fuerte. De ahí que ya es impostergable ir disminuyendo las distancias en todas direcciones, una de ellas es en la inmediatez de lo cotidiano, en esos espacios vitales en los que nos estamos reconformando como seres humanos con otros seres humanos y lo primero que tenemos que reconocer es que somos diferentes, porque eso es lo que permite acercarnos, comprendernos y en especial aceptarnos.

\section{DESARROLLO}

1. Individuo y sociedad mexicana

Un aspecto central para considerar también es que como individuos estamos influenciados ampliamente por el contexto socioeconómico, cultural, político entre muchos otros factores que actúan de diversas formas. Cada individuo bajo este contexto hace propias sus particulares circunstancias existenciales de vida cotidiana, proceso que lo lleva a asumirse como un miembro más de la sociedad en que se encuentra. (Covarrubias,2002: 21).

En consecuencia, este proceso conlleva al desarrollo de concepciones aisladas de la realidad, desarticuladas y fragmentadas. Se incorpora a tal grado como una forma de pensar lo real que se hace práctica y se vive como microhistoria existente. De ahí que el aspecto de la objetividad se vea afectado por la influencia que lo social impone al individuo, cuya subjetividad se hace manifiesta en el comportamiento y concreción de ideas desplegadas en lo cotidiano de la relación interpersonal.

Así el sujeto encuentra su identidad con la sociedad, tiempo, cultura, proyecto histórico de una comunidad y una clase social. La mercantilización de la existencia debida a la expansión del mercado y globalización de la cultura, ha provocado la disminución de la sensibilidad y en especial en lo referente a los procesos formativos, por lo que se vuelve urgente la reflexión de este nuevo reto en todos 
y cada uno de los espacios y tiempos en que haya oportunidad de hacerlo.

Para profundizar en las implicaciones de este reto, es claro que en la época actual el estudio de la formación humana de docentes no puede limitarse a una toma de conciencia enajenada. El ser humano vertido al exterior se diluye en la globalidad, pierde su identidad ya que se ve reflejado fuera y lejos de sí mismo, "perdido o encontrado" en el mundo de la razón y más la razón técnico-instrumental, que a toda costa busca y encuentra las maneras de evitar la expresión de las emociones y sentimientos y deja a la afectividad relegada a un segundo plano o la descalifica en aras de hacer efectiva la objetividad.

La interioridad del Yo idéntico a sí mismo (identidad) se disuelve en la totalidad y lo humano se hace exterior. Es la verdad (del materialismo) la que sostiene al hombre y no el hombre que busca sostenerse en la verdad. La identidad de lo subjetivo de la conciencia trascendental se ve destruida por un mundo razonable. Tal parece que es imposible la congruencia de la interioridad desde la instuición, la percepción o cualquier otra manifestación de la interioridad. "Todo transcurre como si el Yo, identidad por excelencia, al cual se remontaría toda identidad identificable, fracasara consigo, no llegara a coincidir consigo mismo. Si la interioridad no es interior, entonces el Yo es otro y la identidad es un fracaso cuando se vuelve alienación de significaciones ideológicas, "cuando el Yo se transfigura en preso".(Lévinas, 1993, 83)

La posmodernidad intenta dejar atrás la lógica del discurso de la identidad, es decir, la subjetividad es una producción sociocultural, que vuelve dependientes a los sujetos consumidores de estos modos de ser. Se abre la posibilidad de "lo otro", de lo excluido y el sujeto se pierde en la búsqueda de nuevas posiciones "disolviendo identidades que siempre fueron imaginarias" (Acevedo, 2010).
Al verse comprometida la identidad y no haber congruencia entre el ser personal y lo que se vive, la personalidad se desestructura y la manera en que resuelve este problema es aferrándose a un soporte que le dé contención y estructura y esto es la base del comportamiento adictivo. Ovejero (2000) concluye que el comportamiento adictivo es la búsqueda de una identidad. Tal vez sea por eso que en nuestra época se puede ver el despliegue de muchas conductas adictivas.

Efectivamente, tal parece que la adicción dota de sentido a la persona que experimenta el vacío, la soledad, la infelicidad. "Ser adicto a..." significa para el sujeto la adquisición de una identidad definida frente a las vivencias de no ser que la antecedían. Por lo tanto, los objetos de consumo tienen la siniestra ventaja de ser donadores de identidad" (Fischbein, 2009).

Se puede concluir que la subjetividad adictiva es un tipo psicosocial instituido (Lewcowicz, 2000) donde la adicción se desarrolla en la persona que empieza a repetir la misma actividad y construye el concepto de sí mismo (identidad) alrededor de ese centro (Millé, 1998).

Regresada la mirada en particular a la sociedad mexicana, vemos su entrada al proceso de transición institucional debido a la exigencia que le hacen los organismos financieros internacionales (FMI, OCDE, BM, entre otros), los desafíos sociales, económicos, políticos, etc. Dicho movimiento se hizo necesario por la inoperancia del llamado modelo centralizado, compuesto por el presidencialismo autoritario, partido hegemónico, corporativismo sindical, intolerancia, burocratismo y corrupción entre otros, que ya no se pudieron sostener ante la exigencia que dichos organismos antepusieron para otorgar préstamos. (Miranda, 2001: 168).

La sociedad mexicana mediante la educación y los procesos de formación y actualización pretendió ajustarse a los requerimientos que de manera impostergable se imponían y 
hacían presentes también en otras culturas, debido a que los organismos financieros ya no estaban dispuestos a prestar dinero de no cumplir con estos cambios. La educación como factor base, fue tomada sólo para preparar los cuadros profesionales requeridos, es el ejemplo más socorrido en cuanto la formación de cuadros técnicos para la preparación de mano de obra calificada y de acuerdo a los estándares que la misma tecnología aplicada en las grandes empresas transnacionales, en sus procesos productivos necesita.

Entonces, socialmente hablando, las políticas educativas estuvieron orientadas a que tanto la formación como la actualización docente se convirtieran en la punta de lanza del Estado para hacer frente a los problemas que se tenían en lo económico, político e ideológico. Se buscó la profesionalización del magisterio con la intención de contar con los elementos suficientes para adecuarse también a los cambios y ser un agente operativo que le permitiera transmitir los conocimientos y actitudes en una sociedad globalizada en franca apertura.

En México, se presenta un sin fin de matices regionales, en cada uno de los estados que lo componen. Esta parte del país, delimitada como frontera norte, se caracteriza principalmente por el auge y empuje socioeconómico propio de la región, muy influenciada por la muy cercana relación que mantiene con el estado más próspero de los Estados Unidos, como lo es California. Es significativo también que la gente se caracteriza por ser franca, sincera, muy hospitalaria y en ese sentido es algo muy presente identificarnos con orgullo por ser cachanillas, de Mexicali, B.C., México.

Por otra parte, no negamos la influencia de los problemas propios de una región en franco aumento poblacional, las complicaciones de un lugar donde confluye un amplio número de compatriotas que llegan de otros estados de la República, en busca de una buena oportunidad como para pasar luego al vecino país, y que al no lograrse se hace presente la necesidad de quedarse, ya sea en forma provisional o en forma definitiva en estas tierras.

Esta situación es una constante, porque son muchas las personas que intentan una y otra vez esta hazaña y al no lograr su meta, entonces buscan otras opciones y ahí es cuando cambia la perspectiva y se ven en la disyuntiva de hacerse un lugarcito para vivir, trabajar, estudiar, establecer vínculos, entre muchas otras cosas, una de ellas muy importante es la misma educación para sus hijos e hijas, antes que pensar en el fracaso o en definitiva regresarse a sus lugares de origen.

Al presentarse estos acontecimientos, las autoridades tanto federales como locales han tenido que abocarse a dicha problemática, pero ante tal diversidad de formas de ser y hacer de las personas, por lo general, quedan asuntos pendientes. La educación y en concreto las escuelas siguen haciendo falta $y$ es en este punto que queremos hacer una pequeña reflexión más, consideramos que eventos educativos como este, siempre hay que revalorarlos, porque son un campo fértil donde se siembra la inquietud y con la buena intención para hacer algo positivo al respecto, aprovechando la oportunidad de compartir la información en este medio.

Una sociedad como la nuestra, se caracteriza por hacerse cada vez más presente la racionalidad, identificada dentro de la ciencia moderna en el despliegue de la tecnología que se entrevera sin medida alguna en la cultura, debido a su capacidad de expresión práctica en general. Es por esto, como dice Ladrieri (1978), que se ha dado en tomar a la ciencia como una manera de apropiarse de la realidad, es así asumida para actuar efectivamente sobre el mundo que nos rodea, orientando la mirada a lo que conviene, lo que abona a seguir los pasos de una racionalidad que mira al futuro sin darle mayor atención a lo vivido en el presente. 
Pero entonces: ¿Qué podemos entender como ciencia moderna o la modernidad misma? ¿Cuál es la condición del hombre? ¿Qué beneficios se tienen como sociedad? ¿Qué situación prevalece? En general se habla de una pérdida de sentido, desde donde se cuestiona a la vida misma, en cuanto a las posibilidades de hacer algo en una sociedad contemporánea donde lo que menos se tiene es aprecio por el otro y donde el mercado de la oferta y la demanda ha sentado sus reales. Hay un desencantamiento por el presente, no se quiere recordar el pasado y el futuro no es del todo halagador. (Berger y Luckman, 1997).

Ahora bien, no es la intención ni que deseemos se presente un panorama pesimista, es simplemente que en los más diversos escenarios y planteamientos teóricos, metodológicos, paradigmáticos, entre otros, en forma recurrente se hace este tipo de señalamiento; la condición moderna como que se diluye y empieza a ceder su lugar a lo que se ha denominado posmodernidad, sin que ello sea tampoco motivo de esperanza, porque no falta quien diga, que es más de lo mismo en el mejor de los casos, porque ahora se retoma la subjetividad orientada al descentramiento y la discontinuidad. (Tejeda, 1998).

2. Cultura, educación y globalización en México

Así tenemos que de diversas maneras, se ha caracterizado a la sociedad moderna y su expresión cultural en lo concreto, por la obsesión de una vida corrientemente pragmática, por las dificultades crecientes para disminuir la pobreza y otras incontables problemáticas, como la imposibilidad de la razón humana, para encontrar sentido y significado a la realidad objetiva y esperanza del mundo que tanta falta hace en estos momentos. Estas se han interpretado como un decaimiento sociocultural de la modernidad, identificada hoy como posmodernidad y hasta se ha llegado a nombrar en los últimos tiempos como la expansión de manifestaciones identificadas como "new edge". (Guerrero,2006:9).

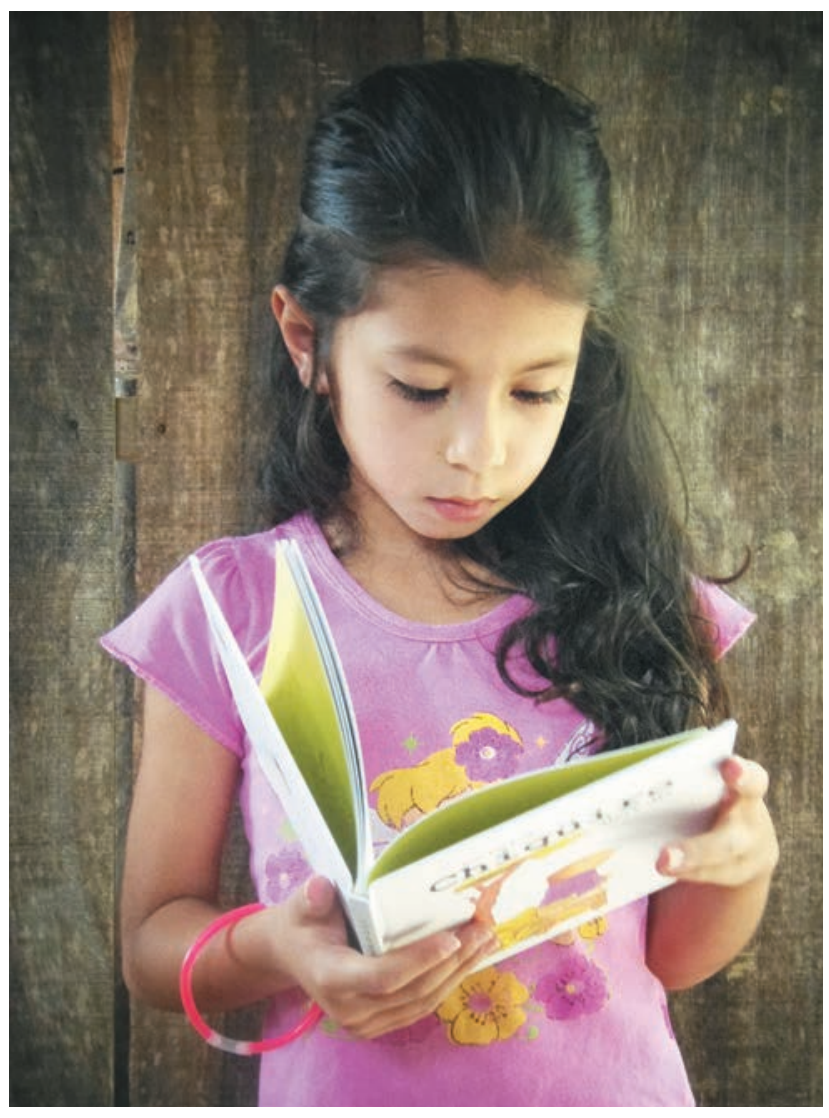

Por otra parte, en las conciencias caracterizadas por un dualismo entre lo espiritual y material, ya no hay el menor reparo en reflexionar al respecto, se acepta la dualidad como algo natural, donde lo que menos importa es la espiritualidad, no hay interés en buscar el equilibrio, sino que a pesar de lo deteriorado de la vida que se vive hoy, prefiere el sacrificio, soportar las insalvables molestias e inconvenientes en el diario vivir en solitario. (Ramos, 1997:3).

De ahí que la educación recobre su importancia en el sentido propio de favorecer una conciencia que recupere el valor mismo de la libertad, su dignidad humana y eleve su nivel de existencia. Un punto de partida para reconformar su humanidad, porque de lo contrario sus avances científicos y tecnológicos se volverán contra él y ya no se diga la organización social que cada vez es menos organización y no hay visos de una prevalencia de relaciones colaborativas.

No negamos que vivimos en una sociedad en constante cambio, transformaciones e inno- 
vaciones, cada vez las distancias reales y virtuales se acortan, se busca afanosamente por los más variados medios la conformación de bloques económicos, acercamiento y unificación de políticas y en general una tendencia a lo que llamamos globalización.

Entendida ésta como un proceso constante de expansión del capitalismo, buscando abrir el mercado para la introducción de mercancías, sean éstas de tipo simbólico o de productos. Se habla de las bondades de este tipo de planteamientos, se invita a formar parte del mismo, a contribuir al mejoramiento de diversas maneras, pero no se habla de las consecuencias: superficialidad espiritual, deterioro personal, pesimismo, estrés, violencia y aislamiento. (Vilchis, 2003: 9).

En cuanto al individuo, la educación se considera esencial, aportando los elementos para desarrollar a cabalidad capacidades y potencialidades que como persona posee. Es la educación la que transmite un sentido, un por qué y para qué, mismos que no quedan exclusivamente en lo intelectual, sino también abarcan el campo vital de su existencia tanto en el área afectiva como psicomotriz.

Educar al hombre/mujer remite al deber ser, ya que éste atiende al ideal humano, procura que sea consciente de lo que vive, lo que significa que atienda a su relación con las personas y la calidad del compromiso que pone en lo que hace. Aprovechar la educación con la concepción que es medio y no fin en sí misma, no tanto en su sentido conservador sino revalorando también las dimensiones transformadora y crítica, una perspectiva abierta por la condición humana y la complejidad que le es propia, es nuestra apuesta.

La libertad es la máxima expresión del hombre y la mujer. Al tomar decisiones y la educación participa activamente en el desarrollo de este proceso, desde el momento que se le considera consustancial a la persona. Promue- ve las creencias, costumbres y tradiciones, brindándole al individuo un sentido, conforma una identidad, desarrolla un compromiso, traduciéndose en una confianza sobre una realidad, le permite estar en un presente y vivir satisfecho sin angustiarse por el futuro. La educación es precisamente la que viene a remediar la construcción de su falta de identidad.

En cuanto a la globalización en sí como proceso de homogeneización, es evidente que las culturas o naciones enteras están destinadas a desaparecer. Asumido desde la perspectiva de quienes las tienen como obstáculos a superar, porque no son necesarias y menos importantes para la lógica del mercado actual. Poco valiosas porque no se les ve posibilidades de constituirse como economías fuertes (Arriarán, 2001:25).

Esto por supuesto tiene sus consecuencias, como por ejemplo que las culturas tiendan a disgregarse por efectos de la migración, por la transnacionalización económica y cultural. En contra respuesta, se dan movimientos como la mundialización y la regionalización que buscan reivindicar su patrimonio cultural y asimilar sus condiciones históricas, sin perder su identidad y expresar sus necesidades por sus medios y condiciones.

Este tipo de resistencias presentes por el avance mismo del dogmatismo y la violencia generada por políticas neoliberales y la globalización, que ignoran las culturas existentes, violentando y reprimiendo cualquier manifestación que se oponga a verlos como simples centros folklóricos y de interés turístico y a los cuales se les tiene que sacar provecho.

Hay que reconocer que la globalización está aquí, ha dejado atrás al humanismo por anteponer lo económico sobre cualquier consideración del hombre/mujer, así como la necesidad de reflexionar en la acción al respecto, procurando captar su propia moral y ética, para comprender mejor su funcionamiento. $\mathrm{O}$ 
tal vez mejor sería oponerse a ella y criticarla por la barbarie con que actúa y en especial poniendo énfasis en la pérdida del humanismo y sus consecuencias; como la enajenación, aislamiento, soledad, despersonalización, etc. (Alcalá 2004: 302).

A lo primero se le conoce como la globalización de segundo orden, propuesto por Apel, donde se recupere precisamente su presencia en el ámbito de la cultura y por otra la moral. Así la expresión de la cultura de occidente no chocaría con otras culturas, propiciando un diálogo intercultural. Se acabaría el problema moral al lograr la justicia en una sociedad multicultural y se rescataría al individuo, la moral y el humanismo. Estas propuestas necesitan ser llevadas a la práctica y pensamos que tal vez la formación de docente podría aportar algo al respecto.

Desde esta perspectiva entonces encontramos que el/la hombre/mujer ha ido construyendo una serie de concepciones, proyecciones y maneras de ser que le han permitido ir conformando las culturas. Culturas, en plural porque una sola no ha sido suficiente, sino que cada una obedece a una muy particular forma de comportarse y constituirse en una sociedad.

Y como parte del roce y acercamiento cada vez mayor entre culturas, se desarrollan formas de tolerancia que permiten ciertas expresiones de libertad de conciencia, para manifestar las más diversas formas de ser y hacer de las propias culturas desde la misma diversidad, situación que beneficia a la sociedad en general. (González, Carbajal, 2000).

Teniendo como antecedente inmediato las políticas educativas con un origen neoliberal, se siguen dando grandes debates en cuanto a quienes están a favor y otros en contra, porque aquí se hacen presentes también influencias tanto internas como externas. Esto hace por supuesto que las propuestas en el campo de la educación se encuentran con un ambiente significado por la controversia. (Arriarán, Beuchot, 1999).

En el fondo lo que realmente se está cuestionando es el tipo de hombre/mujer que se quiere formar, por las mismas circunstancias históricas, los intereses tanto del gobierno en turno como de los organismos financieros internacionales, que no dejan de hacer presencia, buscando afianzar políticas económicas, financieras, culturales, educativas y sociales en beneficio de unos pocos.

Condiciones que apuntan hacia la inducción de hombres/mujeres, ya caracterizados por Fromm (2004), como para que a fin de cuentas sean útiles al modelo económico, que se inserten sin resistirse y sin dificultad al proceso productivo, que sean afectos al consumo inconsciente y fácilmente influenciables y que sin lugar a dudas, en estos tiempos se hace más que evidente en las aulas.

Nuestro país no puede estar al margen del predominio del individualismo, desde el marco económico del capitalismo y en concreto del neoliberalismo que priva en la actualidad. Aquí queremos rescatar el punto de que sin considerar demasiado dichas tendencias, se trata de un individuo singular, y que es una persona en su singularidad inmersa en un contexto social, que le representa oportunidades abiertas para vivir integrada y constructivamente. En ese sentido se pretende buscar no tanto el tener, sino el ser de manera más reflexiva, que implica lo que una persona llegue a ser y hacer buscando hacerse presente en su oportunidad. (Fromm,1998).

En una condición psicológica como esta, de presiones provocadas bajo el marco predominante de los modelos económicos, de producción y de consumo, es evidente que se imponen sólo algunos de los aspectos del carácter social del individuo, donde junto con otros individuos habrán de dar respuesta a las diversas situaciones que los demanden. 
Otra vez se hace necesario hacer una profunda reflexión, sobre ¿Hasta qué punto el individuo como persona se resiste a incluirse en un proyecto? Donde no encuentra sentido grupal, ni beneficios comunes y tiende entonces a necesitar o querer recluirse para conseguir manejar su propia condición, buscar la felicidad, su propia expresión y su libertad vista como singularidad, sin lograrlo debido a que se encuentra en su interior separado de sí mismo y de los demás. (Fromm, 1995).

En los proyectos que hace con otros no se incluye, no participa ni en forma generosa, porque no cuenta ni consigo mismo ni con los demás, es decir, la persona se encuentra alejado de su vínculo esencial con su sí mismo y esto disminuye el alcance de las expresiones dinámicas de su existencia.

Por eso insistimos en que la persona antecede a la concepción misma de individuo o sujeto en su expresión más amplia, y es condición de la persona revalorar desde esa misma singularidad, que se encuentra formando parte de la sociedad, con obligaciones y responsabilidades, pero también con derechos y beneficios. El respeto como valor es fundamental, porque permite relacionarnos con un sentido de independencia, de crecimiento y desarrollo y no dejarnos llevar por la inercia, donde lo que menos se aprecia es la libertad del otro. (Fromm,1980).

Si queremos ir más allá de nuestros cuadros mentales, es necesario descubrir los factores que esclavizan para vivir plenamente. Liberarnos de nuestras adicciones posmodernas. Sólo avanzamos en profundidad y plenitud si somos respetuosos y comprometidos con todos los aspectos que implica vivir, siendo uno de ellos aceptar como principio, para ya dejar de sufrir por la infinidad de situaciones no están a nuestro alcance cambiar. De ahí que lo primero que hay que asumir, es cambiar nosotros primero antes de querer que los otros lo hagan.
Es decir, necesitamos plantear la situación de la educación desde otra perspectiva, que no sea exclusivamente de la teoría economicista, donde el hombre es visto únicamente como individuo, que sabiéndose parte del sistema social satisface sus necesidades. Esto por desgracia lo ha llevado a una concepción donde prevalece el sistema de recompensas y castigos, por tanto todo adquiere un carácter mercantil, donde cada acción tiene un costo y hay que pagar lo que corresponde. (Munguía, Castellanos, 2001).

Estos elementos están presentes en lo que conocemos como cultura, ahí es donde se comparten y experimentan entre otros estos valores, que vistos desde una perspectiva mucho más amplia es recuperación misma de la dignidad humana. Pero no son los valores desde un punto de vista de la eticidad en lo abstracto, sino desde la praxis misma que caracteriza su actuar cotidiano, con un sentido histórico social que le es propio. (Yurén, 1995).

Atendiendo más concretamente a lo que se refiere a una educación desde la interculturalidad y/o multiculturalidad, entonces de lo que se trata es poner mayor énfasis en la misma diferencia, porque así tendríamos una actitud más orientada hacia la diversidad, el pluralismo. Si partimos de lo que nos distingue tal vez podamos encontrar las pautas que nos conectan, porque es preciso indicar que no todo es reducible, sino que hay también otras muchas maneras de decir lo que somos como personas.

Mientras tanto, no dejar de tener presente que se sigue haciendo presente con gran fuerza la tendencia homogeneizadora. Por eso proponemos que se reflexione más al respecto. (Arriarán,2001). Misma acción que como apuntamos, acerca de la constitución del ser humano y de su posicionamiento como ser social en la matriz cultural.

En el caso particular de la escuela mexicana, poco se hace al respecto, los valores y su ense- 
ñanza solamente son abordados en lo abstracto, de manera indirecta y muy superficialmente. Se le da mayor importancia a la enseñanza de las matemáticas y el español, que son conocimientos considerados como prioritarios. Esto, a su vez, no impide que los/las estudiantes se las ingenien para asimilar valores que la misma escuela genera, a pesar de que la educación sea el sitio para construir conocimientos valiosos, significativos, y representativos, entre otros (Elizondo, Ghosh, Tarrow, 2002).

Con referencia a la educación básica, se ha encontrado que el proceso de adquisición de las nociones tanto de lo cultural como sociales se fundamenta y asimila principalmente con relación a los determinantes históricos del contexto propio donde se encuentra viviendo cotidianamente y a las capacidades de comunicación, de expresión, y de las formas que encuentre para desarrollar su propia responsabilidad para enfrentar los requerimientos de la vida escolar. De esta manera activa y operante, asume y hace propios valores tales como el respeto y cuidado de cómo vive la vida, la verdad, el amor y otros que son encarnados al afirmarse directamente en su contacto con otras personas. (Cantoral,2000).

Para el buen desarrollo de este proceso, es importante recuperar el mismo contexto de la enseñanza, tomando en cuenta que varía de una escuela a otra. Una diferencia es la particularidad real de acción práctica que realizan los profesores privilegiando lo que en el aula se hace posible o no, porque como mediadores, también anteponen sus propios valores, cultura, forma de ser y hacer las cosas, no del todo conscientes, porque así es como también ellos aprendieron en su momento lo que ahora practican en sus espacios vitales de la escuela.

Otra diferencia más es lo relacionado a lo que tienen en común las diversas prácticas de los/las docentes, independientemente de los tiempos y las distancias, hay similitudes que los identifican como trabajadores de la educación, en los muy distintos niveles que se desarrollan y son recurrentes de forma sorprendente. (FuIlan, Hargreaves, 1999).

En cuanto a los profesores que laboran en la educación básica, se han hecho intentos para fomentar los valores en la escuela, como una fuerte preocupación de las autoridades para que precisamente ellos sean los portadores y difusores de los mismos. Según las últimas reformas, se ha hecho esto posible en la asignatura de Formación Cívica y Ética, que termina favoreciendo más a los aspectos cívicos que a los éticos, pero con poco interés o motivación para los estudiantes, al no encontrar significación o sentido, porque los contenidos se plantearon como necesidad social que se ha llevado al proceso mismo de la formación inicial. (Schmelkes,1998).

3. Formación docente y procesos de actualización

El campo de la formación de docente es complejo y no menos polémico por sus variadas dimensiones y problemáticas que aborda. Una de ellas en la dimensión política; asignación de recursos financieros, de internacionalización orientada a la formación de investigadores y la flexibilidad dentro del discurso educativo. Ya iremos dándonos una idea desde dónde o por dónde comprenderlo mejor hoy, con el contexto ya señalado en la globalización, porque el concepto mismo de formación de docente hay que redimensionalizarlo y no se quede en lo técnico-instrumental. (Romo y Matute,2000: 9).

Aquí privilegiamos la formación de los/las docentes desde la perspectiva que son considerados como sujetos sociales que posibilitan un cambio en las formas de pensar de los/las estudiantes y la propia. El concepto es retomado en sus diversas acepciones y una es la que se relaciona con el proceso de vida, que implica la necesidad de dar forma, de formar en sí y de formar-se. Recobrándose la capacidad de desa- 
rrollar la transformación mutua, entre docentediscente, teniendo como base la alteridad y presencia de otros en el mundo individual primero que se abre al colectivo.

En el caso de México, la formación adquirió importancia, porque en la década de los ochenta se hizo patente una crisis financiera, que repercutió en todo el país y en particular causó un gran deterioro en la relación pedagógica, disminución y conflictos entre los investigadores, amén de la pérdida de prestigio del universitario y los títulos profesionales que hasta entonces se ostentaban con valor y reconocimiento social y que en los noventa se hizo un gran esfuerzo por recuperarlo, a la fecha esto no ha sido posible. (Didou,2000: 19).

Las causas, entre otras, fueron la globalización en cuanto a la formación de recursos humanos y la capacidad para realizar la investigación, dos factores imprescindibles para la competitividad, el bienestar y el mantenimiento de la estabilidad social. Nuestro país no realizó las acciones necesarias para dar las respuestas requeridas, porque en los profesores había deficiencias en grados escolares.

Este debilitamiento en la identidad de docentes y las profesiones, necesariamente repercute en los planteamientos curriculares, como punto de referencia de las mismas propuestas formativas, que en la actualidad se conoce como flexibilidad curricular. Así se pretende desarrollar competencias genéricas y diversificar las especializaciones para optar mejor por cursos sueltos y diferentes formas de estrategias para su aprendizaje como por ejemplo; a distancia, en línea, por Internet, y otras.

Este tipo de ejercicios no es hasta el momento del todo agilizado, por la misma falta de experiencia y por otra el financiamiento ha sido insuficiente. Su desarrollo continúa porque es parte de los requerimientos para ser parte del mercado educativo globalizado y digitalizado de hoy.
La misma globalización ha traído un mayor intercambio en materia de políticas educativas, por vías de comunicación electrónica y visuales, mediante la promoción de eventos financiados por organismos internacionales, donde se proponen programas, materiales, estrategias y otras concepciones que se presentan por igual, procurando encontrar soluciones y propuestas. Todo ello bajo una perspectiva de globalización en teorías del aprendizaje, metodologías, didácticas, estrategias, procedimientos, materiales, entre otros. (Sarramona,2002:65).

La escuela misma es generadora de una serie de valores, condiciones sociales, culturales, económica, política e ideológica para no tenerlas presentes. Porque como institución es instituyente e instituye todo un sistema de formas de ser y hacer. No es aceptable considerarla como un espacio neutral, porque entonces corremos el riesgo de caer en un tipo de ideología, que no permite avanzar en la comprensión de lo que ahí acontece y en especial la necesaria reflexión sobre esto. (Bourdieu,1990).

En todo este acontecer de la vida cotidiana: ¿Qué papel juegan los/las docentes? ¿Qué posibilidades tienen de influir? ¿Qué significa para ellos/ellas su propia labor? Son preguntas que quedan ahí, porque dar respuesta a las mismas, sería desde un marco de referencia con el cual no necesariamente tenemos por qué estar de acuerdo. Por otro lado, es un protagonista no del todo valorado en su justa dimensión y eso es una realidad.

Su situación se complica un poco más, cuando hablamos de un lugar tan controversial como es el contexto fronterizo, donde confluye un muy variado grupo de personas con orígenes culturales distintos y que por las mismas circunstancias, se han visto en la necesidad de compartir un espacio y tiempo con otros, no convencidos de la relación. Esto por supuesto se refleja en la escuela y el/la docente tiene que dar respuestas lo mejor posible. 
Bajo estas condiciones el/la docente ha sido identificado como agente socializador, donde bajo la concepción de una pedagogía fronteriza, tiene que atender ante todo la diferencia, compartir lo más posible la inclusión y hacer explícitos los antagonismos sociales, desde el planteamiento de lo público, porque ya no es posible que la escuela siga siendo considerada como separada del ámbito en que se encuentra funcionando, tanto real como por su adscripción ideológica.

No olvidar que es representante también de una propuesta gubernamental que se cristaliza en planes y programa, se hacen efectivos en los libros de texto, sin dejar de observar también, precisar y atender la pluralidad para formar críticamente al ciudadano con un sentido de igualdad. (Giroux,1997).

Esto por supuesto no es fácil que digamos, porque se ponen en juego en él/ella mecanismos de aceptación/rechazo, que le hacen entrar en una constante lucha entre lo propuesto en los programas oficiales, las exigencias propias del aula y su concepción como el deber ser. Un estudio realizado al respecto, obtuvo resultados pocos halagadores, es revelador al ser para los/las docentes problemáticos, excesivos y poco satisfactorios. (Esteve, Franco, Vera,1995).

Por otra parte, una de las propuestas actuales derivada de las diferentes reformas educativas, que se han venido dando en los últimos años, es que la enseñanza procura que sea centrada en el estudiante. Esto no ha sido del todo bien logrado, porque una cosa es el cambio por decreto y otra las prácticas cotidianas que se hacen efectivas en el aula. Recordemos que vivimos en una cultura centrada en la autoridad y un ejercicio irrestricto del poder. ¿Qué posibilidades tienen los/las estudiantes de hacer algo más que escuchar? (Comboni, Juárez, 2000).

Una de las estrategias que se han documentado al respecto, ha sido en cuanto al manejo de los temas de manera, cada vez más integrada y relacionada por parte de los/las docentes. En este aspecto, el/la estudiante tiende a ser incluido en una mayor actividad y que, a su vez, sea aportador según el contenido trabajado.

Repetimos que esto ha sido tomado en cuenta, mas no que sea algo posible de generalizar como dado. En concreto lo que se propone es recuperar al estudiante como sujeto protagonista. (Toledo et al,1998).

En otras investigaciones, se menciona que los cambios al interior del aula, desde el punto de vista valoral, siguen estando mayormente centrados en el/la docente. Es quien se asume como el actor principal, condiciona la estructura de participación y los contenidos son más trabajados al interior del propio campo disciplinario, pero no relacionados con valores que adquieren sustancia, como por ejemplo en el diálogo acerca de situaciones vividas. (García, Vanella,1999).

Esto, por supuesto, tiene sus repercusiones tanto en el ámbito psicológico, sociológico y cultural de los/las estudiantes. Donde prima un ambiente de estas características, pocas posibilidades quedan para intercambiar puntos de vista, concepciones y visiones que les son propias. La afectación de la diversidad, pluralidad y las percepciones que se van tomando del contexto mismo en que viven y esto con mayor razón en la frontera se complica.

$Y$, al respecto de complicaciones de este tipo, en estudios desde la perspectiva de género, se presentan de manera recurrente, actitudes de rechazo hacia el directivo en el que se centra el poder y de aplicar, a su vez, el control sobre los/las estudiantes como sus respectivos subordinados, con marcado énfasis diferencial entre los niños y las niñas. (Parga, 2004).

4. Algunas perspectivas de la formación y globalización

Se hace imprescindible conocer las diferentes propuestas aplicadas a lo largo de los últi- 
mos años en la formación, en el contexto de la globalización, los cambios que se han presentado y no sólo hacer referencia a estructuras, sino el proceso mismo de formación. De ahí la importancia de revalorar al concepto de aprendizaje de los docente y lo correspondiente a experiencias. Siendo el/la docente el punto central en esta concepción, como sujeto activo y participativo en su propio proceso formativo. (Ávalos, 2000: 85).

La formación entendida así tiene varias condicionantes, no del todo sencillas de cumplir, por la diversidad de los/las participantes, que las propuestas tratan de observar. Dentro de ellas se mencionan: la diversidad de historias de formación, diversidad de énfasis en la formación previa con la que cuentan los/las estudiantes, diversidad de intereses de los/las demandantes y diversidad de intencionalidades en el diseño de los programas.

Teniendo estos antecedentes ya comprendemos mejor tres diferentes tendencias en la formación de docentes que se han venido perfilando, entre ellas: el/la docente como culturalizador, docente como técnico y docente como especialista. (Sepúlveda, 2000: 123).

La globalización exige la existencia cada vez mayor de personal más y mejor calificado, para estar a tono con los requerimientos de la industria y la producción, así como de los avances tecnológicos que privan en el ambiente internacional. La formación ha sido orientada en ese sentido, los modelos, tendencias y propuestas han ido evolucionando también. Estar atentos a estos requisitos, con los ojos bien abiertos y preocupados como personas responsables es una actitud que será siempre bienvenida.

Ya refiriéndonos al ámbito local, hay investigaciones realizadas sobre la diversidad que priva en las escuelas públicas, en una frontera como en la que nos encontramos los bajacalifornianos. Se menciona de manera contundente cómo entre los mismos estudiantes se estable- cen ciertas diferenciaciones de manera muy precisa. Porque no es muy aceptable entre ellos la presencia de quienes vienen de otros estados y en particular del mismo interior de la República. Los señalamientos son peyorativos y despectivos en diversos grados para significar el estatus que tienen dentro del aula de acuerdo a sus diferencias, también cuanto lo económico y cultural, por sólo citar algunas. (Ochoa, 2004).

En otra investigación se analiza el poder que ejerce el profesor dentro del salón de clases haciendo gala de lo que se le denomina como arbitrariedad cultural. De esta manera el/la estudiante solamente le queda resignarse con un papel de sumisión, porque este poder es precisamente lo que legitima la autoridad de los docente $y$ todo lo que diga o haga es un conocimiento cierto. (Martínez, 2005).

Así el binomio poder y saber queda a buen resguardo por parte de los docente, quien lo ejerce con discreción sin hacer diferenciación alguna, dentro del aula tiende a la homogeneización cultural de éstos. Recuérdese que el/la docente es un agente que tiende a difundir las concepciones de una determinada ideología que le imponen por medio de los planes y programas. En buena medida también van implícitos impregnados de su ideología personal. (Freire, 2002). Pero también que esto no se da de manera única o sin mayor sobresalto. En cierta forma se presenta al interior de estos procesos resistencias, tanto de docentes como de estudiantes.

Ahí es donde los puntos de contacto tanto de tipo valoral como de la misma diversidad se van dando en la praxis. No quisimos parecer pesimistas, pero sí mostrar en parte la realidad de las escuelas en México y en particular lo que se ha encontrado por medio de las investigaciones tanto en el ámbito nacional como local en la frontera.

Son muy variadas y reveladoras las aportaciones de estos investigadores tanto internacionales, nacionales como locales, por eso 
insistimos que es necesario seguir buscando y haciendo lo posible por encontrar otras vías que permitan vivir en la diversidad de un contexto como el que caracteriza a nuestra frontera bajacaliforniana.

Proponemos que la reflexión en la acción abre nuevas opciones, que las luchas en los diferentes ámbitos, son importantes porque muestran que hay posibilidades de encontrar una mejor forma de convivir en y con la diferencia; con respeto, con responsabilidad, en un diálogo incluyente. Es impostergable hacer efectivos los valores en general y en especial los tres antes mencionados, al interior del aula, para extendernos hacia la construcción de ambientes de aprendizaje y sociales más humanitarios, a fin de cuentas es el sitio, donde el discurso etéreo tiene que ceder su lugar a la esperanza concreta.

5. El/la docente, su formación e interculturalidad

En estos tiempos de prisas sin fin, no es común salirse de la caja mente-tiempo, pensamiento que rige actividades y rutinas, para crear el espacio necesario, donde conscientemente se ubique y dé atención a una pedagógica fronteriza, que haga acto de presencia en el proceso de formación de docente centrado en las inevitables implicaciones entre teoría y práctica, y permita la reflexión crítica que produce conocimiento educativo, que esté vinculado a necesidades sociales.

Decimos que no es común, porque la sobrecarga de actividades nos deja, como docentes, agotados, sin aliento, y desde ese lugar, lo que menos queremos es darnos cuenta del misterio insondable que nos rodea y que reta a estar a tiempo, atento, presto ante el fluir de la vida $y$ atender lo que es inevitable dejar de hacer. La diversidad cultural demanda una especial práctica educativa.

El/la docente antes que función es persona y como tal aquí procuramos atender su propio proceso formativo como docente y se desarrolle armónicamente. Por desgracia esto no es del todo posible; por una parte los procesos formativos están constituidos por contradicciones ideológicas; desarrollar personal preparado para cumplir con las exigencias propias de la globalización y por otra la cada vez mayor falta de empleo y ya no se diga bien remunerado. Los grandes cambios que se han presentado en las últimas décadas y que conocemos como globalización han afectado a todas, todos y en todo a la sociedad. (Anzaldúa,2004: XXI).

La formación tiene algo que decir al respecto, la crisis en que nos encontramos por la globalización no es para siempre, por eso le apostamos a la formación para propiciar en los docentes una toma de conciencia y desde sus propias trincheras hacer frente a la misma. Sabemos que no es la solución, pero sí un elemento importante. Como docente asume entonces una nueva docencia, responde más a los problemas sociales, donde tanto docentes como estudiantes participan en un mundo en constante cambio, con capacidad para investigar, innovar y criticar con sentido propositivo, sabiendo utilizar la tecnología y no subordinándose a ella.

En este último sentido, recurrimos a los términos de interculturalidad, pluriculturalidad y multiculturalidad que en su conjunto identificamos como diversidad cultural. En el fondo estamos hablando de reconocer la igualdad de los individuos, de las personas y sujetos; el derecho a contar con una identidad cultural y en especial respeto, tanto en la migración como inmigración. Entonces contaríamos con una educación intercultural, que entre otras requiere de un marco democrático para su adecuado ejercicio e implementación en las aulas. (López, 2002: 15).

Sabemos que esto no es del todo accesible, o que se cuente con éstas condiciones, pero cada vez hay un creciente interés por la educación multicultural, por la misma necesidad de dar respuesta a los/las docentes y estudiantes migrantes que provienen de orígenes tanto 
cualitativa como cuantitativamente pluriculturales.

En zonas como el norte del país y en específico en el noroeste y más con Tijuana, B.C., esto acontece cotidianamente y ya no se diga respecto a la migración constante desde el interior de la República Mexicana, necesidad que es apremiante atender hoy por hoy. (Jordán, 1994: 13).

Como individuos, sujetos y personas en una sociedad y compartiendo en ella nuestra individualidad, como docentes a la vez que formamos a otros, también nos formamos con otros. Al participar conscientemente y en libertad en esta formación descubrimos lo esencial de nuestra labor: que para ayudar a otras personas, no hay diferencia alguna entre qué se enseña o aprende y lo que uno es, buscando con afán llegar a ser algo más. (Asensio, 2004 : 28).

Bajo esta consideración, reflexionar sobre las culturas (Bourdieu,1990:17), permitirá recuperar algunos aspectos importantes que se presentan en el contexto fronterizo que vivimos, en un sin fin de manifestaciones culturales que reencarnan la riqueza de la diversidad (Díaz,2004:246) que resulta de la confluencia de diferencias significativas en la realidad social y educativa. Las personas son, somos extensivas y portadoras de cultura (Cantoral, 2000 : 25).

Desde esta perspectiva puntualizamos que en la diversidad cultural se encuentra la riqueza (Tirzo,2005: 29), representando una muestra importante el estado de Baja California, donde su población crece y se revitaliza con un sin fin de manifestaciones tanto económicas, políticas, sociales, culturales, psicológicas y por supuesto también educativas (Arriarán, 2001: 35).

La realidad educativa, donde se filtran estas otras múltiples realidades, hay que entenderla desde la acción - reflexión, de la práctica educativa inmersa en la diversidad cultural, labor que corresponde a los/las docentes (Yurén,1995:95). Vivir en este contexto fronterizo, supone un reto para la función y formación del/la docente en educación básica. Al atender a los niños y niñas en el aula, el aspecto de la diversidad cobra vigencia (Parga,2004:45), caracterizándose por expresiones personales y manifestaciones de formas de ser y hacer de los/las estudiantes (Ornelas, 2005: 79).

Es en el aula donde el/la docente tiene que hacer uso de recursos, estrategias y procedimientos para dar respuesta a estas exigencias (Sandoval,2000:151), así como es el sitio para el despliegue de capacidades, habilidades y actitudes que ha desarrollado con los años, traducidas en experiencia (Ornelas, 2000 : 34). Este proceso es cotidianamente repetido, asimilado y adaptado según las circunstancias del contexto en que se encuentra la escuela donde trabaja, de ahí que la reflexión y conocimiento de su praxis generadora es fundamental, porque así se hace posible dar cabida a otras manifestaciones en igualdad de condiciones.

Al pensar en la diversidad, muchas preguntas surgen acerca de ¿cómo dar respuesta a su compleja trama? Lo primero por hacer es conocer y comprender la situación real manifestada, así se contará con la información para aventurarnos a compartir una propuesta que arroje luz sobre las diferencias culturales, su diversidad, trascendencia y tomar cartas en el asunto (Jordán,1994:37).

Es importante que el/la docente sea considerado como actor principal, sujeto activo, la persona comprometida con una labor, que indirectamente a todos compromete. Si logramos que esto sea realidad, daremos un gran paso en la comprensión de la problemática de la diversidad, en el contexto de la escuela, donde el/la docente tiene que valorar la pluralidad de expresiones que se presentan en el aula (García y Varela, 1999:58; Fullan y Hargreves, 1999:71; Ochoa, 2004:56; Schmelkes, 1998: Martínez, 2005:52).

Para nosotros, la formación que mejora la práctica docente y la construcción de sí mismos como personas es la que resulta valiosa 
(Elizondo, Ghosh y Tarrow,2002:54). Su acercamiento a través de la investigación posibilita pasar de la mera reflexión a la acción comprometida con el innovación, cambio, la transformación, (Ferry,1997:13; Fernández,1998:34).

Queremos compartir aquí una experiencia, que desde la misma temática de la formación de docentes (Matute y Romo,2000:163;Anzaldúa y Ramírez,2004:64), ilustra sobre la idea misma de cómo el/la docente hace propio este proceso formativo, desde la recuperación de lo hecho en los años recientes, y poniendo su mirada más concretamente, sobre la diversidad cultural fluyente en el aula escolar a medida que comparten estudiantes y docentes (Giroux,1997:48).

Por otra parte, las relaciones que se presentan en este escenario son a tal grado complejas que es este último quien da cuenta de las maravillas y posibilidades de su labor, guiado por una pedagogía que articula teoría y práctica y no sólo evaluado desde el análisis de la mirada externa y distanciada, no comprometida a fondo por preocupaciones que se quieren fundar el una pretendida objetividad. (Freire,2002:80).

La investigación tiene algo que decirle cuando pasa a ser parte de su proceso formativo, así, la construcción de conocimiento y la realización de la práctica educativa se estructuran bajo el paradigma crítico de investigación-acción. Nosotros planteamos como alternativa, que el/la docente realice investigación, si es o no factible, será su personal elección y en ello va la esperanza también que logre sistematizar e integrar lo que cotidianamente hace tanto fuera como dentro del aula (Imbernón et al,2002:52; Ibernón,2002:87).

La globalización, los avances científicotecnológicos, el protagonismo de los medios masivos de comunicación, la impresionante presencia de las redes de las nuevas tecnologías de la información y comunicación y otras innovaciones, no han llegado todavía a con- juntar una propuesta ética, una opción válida, viable para el desarrollo humano y promovido la libertad individual, personal y del sujeto. Se ha generalizar una lógica del capital, con tintes globales arrogándose pomposamente el título sin fronteras, creando paraísos artificiales y destruyendo mucho de nuestro planeta desde la propuesta de educación ambiental, marginando sectores poblacionales, ampliando desigualdades sociales, etc. (Nieto,2005:100).

La condición humana es así, porque como individuos habitamos este mundo, creamos sistemas sociales, económicos, políticos, ideológicos, educativos entre otros y también una cultura en particular. Según nuestras propias necesidades y nos identificamos con ellos para bien o para mal, porque no a todos y todas beneficia o favorece. El hombre/mujer siguen teniendo la última palabra y llegará el tiempo que nos reconozcamos en realidad como somos: ¡Humanos!..

\section{CONCLUSIONES}

Desde la perspectiva expuesta, la diversidad cultural que se expresa en el aula, en un elemento central de atención y punto de partida de la enseñanza y los aprendizajes promovidos en el aula (Bazdresch,2000:30).

La formación de docentes se hace presente como una práctica generadora de experiencias sociales e individuales, cuyo análisis tiene que hacerse bajo estrategias de investigación-acción.

Ha llegado el momento impostergable de una mayor reflexión sobre la formación de docentes, y llevarla a su realización por medio de la acción, para que el/la docente produzca prácticas creativas orientadas por la misma acción, observando la diversidad y contenedoras de diferencias e instrumentadora de cambios educativos con amplia pertinencia social. (Baggini,2004:87).

Los elementos teóricos implicados en el proceso de conformación de la identidad, personal y fronteriza, sean vertidos en propuestas prácticas y 
recomendaciones de políticas públicas en materia educativa y social que contribuyan al desarrollo de la formación de una identidad humana que posibilite orientar la propia vida y el desarrollo de una subjetividad humana que encuentra sentido al responder al otro desde la transubjetividad también.

Se propone a la investigación-acción como una estrategia metodológica crítica que se encuentra muy cercana a las actividades que realiza el/la docente $y$, por lo mismo, a las posibilidades de hacer investigación de su propia labor docente en el contexto tanto externo como interno del aula, sin perder de vista la diversidad cultural.

\section{BIBLIOGRAFÍA}

Acevedo, J. (2010). Hermenéutica del sí. Identidad narrativa \& Constructivismo en Psicología. Tesis Magíster en Psicología Clínica. Universidad Adolfo Ibáñez. Santiago de Chile, 2010.

Alcalá Campos, Raúl. (2004). Globalización, modernización, ética y diálogo intercultural. En Olivé, León. (Compilador). Ética y diversidad cultural. México: Fondo de Cultura Económica.

Anzaldúa Arce, Raúl E y Ramírez Grajales, Beatriz. (2004). Formación y tendencias educativas. México: Universidad Autónoma Metropolitana.

Arriarán Cuéllar, Samuel. (2001). Multiculturalismo y globalización. México: UPN.

Arriarán Cuéllar, Samuel, Beuchot, Mauricio. (1999). Virtudes, valores y educación moral. México: UPN.

Asensio, José M. (2004). Una educación para el diálogo. España: Paidós.

Ávalos, Beatrice. (2000). El cambio en la formación de docentes. El aprendizaje práctico. En Anzaldúa Arce, Raúl E. y Ramírez Grajada, Beatriz. Formación y tendencias. México: UAM

Baggini, Julian. (2004). El sentido de la vida. España: Urano.

Bazdresch, Parada Miguel. (2000). Vivir la educación: Transformar la práctica. México: Secretaría de Educación Jalisco.

Berger, Peter L., Luckmann, Thomas. (1997). Modernidad, pluralismo y crisis de sentido. España: Paidós.
Bourdieu, Pierre. (1990). Sociología y cultura. México: Grijalbo.

Cantoral Uriza, Sandra. (2000). La identidad cultural en la educación. México: U P N.

Comboni Salinas, Juárez Nuñez, José Manuel. (2000). Resignificando el espacio escolar. México: UPN.

Covarrubias Villa, Francisco. (2002). La otredad del yo. México: Universidad Pedagógica Nacional.

Díaz Cruz, Rodrigo. (2004). Ética y diversidad cultural. México: FCE.

Didou Aupetit, Sylvie. (2000). Políticas de formación docente. En Anzaldúa Arce, Raúl E. y Ramírez Grajada, Beatriz. (Coordinadores) Formación y tendencias educativas. México: UAM

Elizondo Huerta, Aurora, et al. (2002). Valores y formación docente. México: Universidad Pedagógica Nacional.

Fernández Pérez, Miguel. (1998). La profesionalización del docente. México: Siglo XXI.

Ferry, Gilles. (1997). Pedagogía de la formación. México: Facultad de Filosofía y Letras. UNAM.

Fischbein, J. (2009). "El ángel", la adicción y la exclusión social. Controversias en Psicoanálisis de Niños y Adolescentes. Año 2009, No. 5.

Fullan, Michael; Hargreaves, Andy. (1999). La escuela que queremos. México: Secretaría de Educación Pública.

Freire, Paulo. (2002). Pedagogía de la esperanza. México: Siglo XXI.

Esteve, J.M., Franco, S., Vera, J. (1995). Los profesores ante el cambio social. España: Anthropos - UPN.

Fullan, Michael, Hargreaves, Andy. (1999). La escuela que queremos. México: SEP.

Freire, Paulo. (2002). Pedagogía de la esperanza. México: Siglo XXI.

(1979). La educación como práctica de la libertad. México: Siglo XXI.

Fromm, Erich. (2004). Psicoanálisis de la sociedad contemporánea. México: FCE.

(1998). Del tener al ser. México: Paidós.

. (1995). El miedo a la libertad. México: Paidós. (1980). El arte de amar. México: Paidós. 
García Salord, Susana, Varela, Liliana. (1999). Normas y valores en el salón de clases. México: Siglo XXI - UNAM.

Giroux, Henry A. (1997). Cruzando límites. México: Paidós.

Guerrero, Luis. (2006). Hacia una ética para la posmodernidad. México: Gandhi.

Imbernón, Francisco, et al. (2002). Investigación educativa como herramienta de formación de profesores. España: Graó.

Imbernón, Francisco, et al. (2002). La formación y el desarrollo profesional del profesorado. España: Graó.

Jordán, José Antonio. (1994). La escuela multicultural. España: Paidós.

Ladriere, Jean. (1978). El retorno de la racionalidad. Salamanca: Sígueme.

Lewcowicz, Ignacio. "Explotación, exclusión, subjetivación". Ponencia presentada en la mesa subjetividad y globalización. Fundación hacia un nuevo pensamiento político. CTA, 2000

López López, María del Carmen. (2002). Diversidad sociocultural y formación de profesores. Bilbao: Mensajero.

Martínez Escárcega, Rigoberto. (2005). Educación, poder y resistencia. México: Doble Hélice - UPN.

Matute, Esmeralda; Romo Beltrán Rosa Martha. (2000). Diversas perspectivas sobre formación docente. México: Universidad de Guadalajara.

Millé, C. (1998). Identidad, dependencia e independencia. (Primera de dos partes). Revista LiberAddictus. núm 25, diciembre, 1998.

Millé, C. (1999). Identidad, dependencia e independencia. (Segunda y última parte). Revista LiberAddictus núm, 26, febrero, 1999

Miranda López, Francisco. (2001). Las universidades como organizaciones del conocimiento. México: Colegio de México. Universidad Pedagógica Nacional.

Munguía Espitia, Jorge, Castellanos Ribot, Margarita. (2001). La jaula de los deberes. México: UPN.

Nieto Sotelo, Enrique. (2005). Reflexiones en torno a la diversidad cultural. En Tirzo, Jorge. (Coordinador) Educación e interculturalidad. México: Universidad Pedagógica Nacional.
Ochoa Sánchez, Arnulfo. (2004). Una escuela para todos y todas. Educar en la diversidad. México: Plaza y Valdés - UPN.

Olivé, León. (2004). Ética y diversidad cultural. México: Fondo de Cultura Económica.

Ornelas, Gloria Evangelina. (2005). Práctica docente y dinámica cultural en la escuela primaria. México: Porrúa.

Ornelas Tavárez, Gloria Evangelina. (2000). Formación docente ¿En la cultura? México: Universidad Pedagógica Nacional.

Parga Romero, Lucila. (2004). Una mirada al aula. México: Plaza y Valdés - UPN.

Ovejero, A. (2000). La adicción como búsqueda de identidad: una base teórica psicosocial para una intervención eficaz. Intervención psicosocial: Revista sobre igualdad y calidad de vida, ISSN 1132-0559, Vol. 9, №. 2, 2000 , págs. 199-216. Universidad de La Rioja.

Ramos, Samuel. (1997). Hacia un nuevo humanismo. México: Fondo de Cultura Económica

Sandoval Flores, Etelvina. (2000). La trama de la escuela secundaria: institución, relaciones. México: Plaza y Valdés.

Sarramona, Jaume. (2002). Desafíos de la escuela del siglo XXI. España: Octaedro.

Schmelkes, Sylvia. (1988). La formación de valores en educación básica. México: SEP.

Sepúlveda E., Gastón. (2000). Reflexión y acción en la formación de profesores. En Anzaldúa Arce, Raúl E. y Ramírez Grajada, Beatriz. Formación y tendencias educativas. México: UAM.

Tejeda, José Luis. (1998). Las fronteras de la modernidad. México: Plaza y Valdés.

Tirzo, Jorge. (2005). Educación e interculturalidad. Miradas a la diversidad. México: UPN.

Toledo Hermosillo, María Eugenia, Sosa Peinado, Euríce, (1998). El traspatio escolar. Una mirada al aula desde el sujeto. México: Paidós.

Vilchis, Javier. (2003). Persona, educación y destino. México: Plaza y Valdés.

Yurén Camarena, María Teresa. (1995). Eticidad, valores sociales y educación. México: UPN. 